\begin{tabular}{c|c}
\multirow{2}{*}{ EESD'15 } & The $7^{\text {th }}$ International Conference on Engineering Education for Sustainable Development \\
\cline { 2 - 2 } & Vancouver, Canada, June 9 to 12, 2015
\end{tabular}

\title{
INJECTING SUSTAINABILITY INTO ENGINEERING DESIGN PROJECTS
}

\author{
Libby Osgood ${ }^{1,2}$, Wayne Peters ${ }^{1}$ and Stephen Champion ${ }^{1}$ \\ ${ }^{1}$ The University of Prince Edward Island, Canada \\ 2 eosgood@upei.ca
}

\begin{abstract}
Ideal engineering graduates are able to think critically, produce solutions that satisfy multiple stakeholders, protect the interest of the public, and assess their ethical, social, economic, and environmental obligations, based upon their knowledge of engineering principles. Project-based learning is an appropriate forum for students to develop these skills while focused on authentic design problems. In structuring an effective learning environment, intentional effort must be made by educators in all program areas-ranging from the choice of client to the information requested in the final report-to highlight students' greater responsibility within society. The decisions that an educator makes to the framework, deliverables, and exercises for a design project impact the degree to which students will engage in higher level decision making. This paper will discuss the strategies that have been employed in the first and second year projects that encourage students to use higher-level thinking and will introduce how sustainability will be an integral focus of the new Sustainable Design Engineering degree.
\end{abstract}

\section{INTRODUCTION}

The fundamental objective for engineering educators is the transfer of knowledge of engineering principles. Built upon this traditional foundation, ideal graduates are able to think critically, produce solutions that satisfy multiple stakeholders, protect the interest of the public, and assess their ethical, social, economic, and environmental obligations. Accreditation boards have also charged educators to ensure that students consider the sustainability of their solutions (ABET 2015) and understand sustainable development and environmental stewardship (CEAB 2014).

The challenge, then, for engineering educators is to develop learning methodologies that produce engineers who can recognize the many complexities inherent in a design problem, with a specific focus on the sustainability of the design. Project-based learning is an ideal vessel for students to develop critical thinking skills while focusing on authentic design problems. However, these skills don't develop automatically simply because students are designing for a real client or learning within a certain pedagogical framework. In structuring an effective learning environment, intentional effort must be made by educators in all project areas to highlight students' greater responsibility within society. The decisions that an educator makes to the framework, deliverables, and exercises for a design project impact the degree to which students will engage in higher level decision making. The design projects can incorporate sustainability through the framing of the problem, constraints, evaluation of ideas, and impact analyses. Activities can also be performed within the design course but outside of the project to deliver sustainability concepts for projects where the link to sustainability is not immediately obvious.

First and second year students at the University of Prince Edward Island have engaged in design projects with a focus on sustainability for more than 10 years through the 2-year diploma program. As the third year of the new Sustainable Design Engineering degree begins in Fall 2015, sustainability considerations 
will be woven into the curriculum. Students in the multidisciplinary four-year degree will learn engineering in a project-based professional practice environment, employing and enhancing their design skills each semester. This paper will discuss the program, project, and course activities that ensure sustainability concepts are prevalent throughout the degree, as well as a commentary on the efficacy of these techniques.

\section{CONTINUUM OF EDUCATION}

Engineering education is an ongoing, lifetime activity marked by an accumulation of both knowledge and work experience. In the early stages of this progression, knowledge and work experience are acquired through two distinct but sequential processes (Engineers Canada, 2013). First, study in an accredited undergraduate engineering degree program delivers the knowledge while, second, a subsequent fouryear period as an Engineer-in-Training (EIT) provides the work experience. Finally, qualification as a Professional Engineer (P.Eng.) leads to a professional practice career enhanced by continual personal professional development.

In this long-standing model, knowledge increases quickly during studies while work experience tends to lag behind this, only ramping up once employment as an EIT is secured, as illustrated in Figure 1(a). The early "experience gap" which results from this model has two detrimental effects. First, it compromises employment success for new graduates entering the workforce as employers generally look for employees with work experience. Second, and perhaps more importantly, it represents a missed opportunity during early studies to reinforce the knowledge learned with practical engineering experience. It has been shown that co-op programs diminish the first of these effects (Noyes and Gordon, 2011). However, limited research exists to demonstrate the academic benefits of the somewhat separated experience provided by co-op programs.

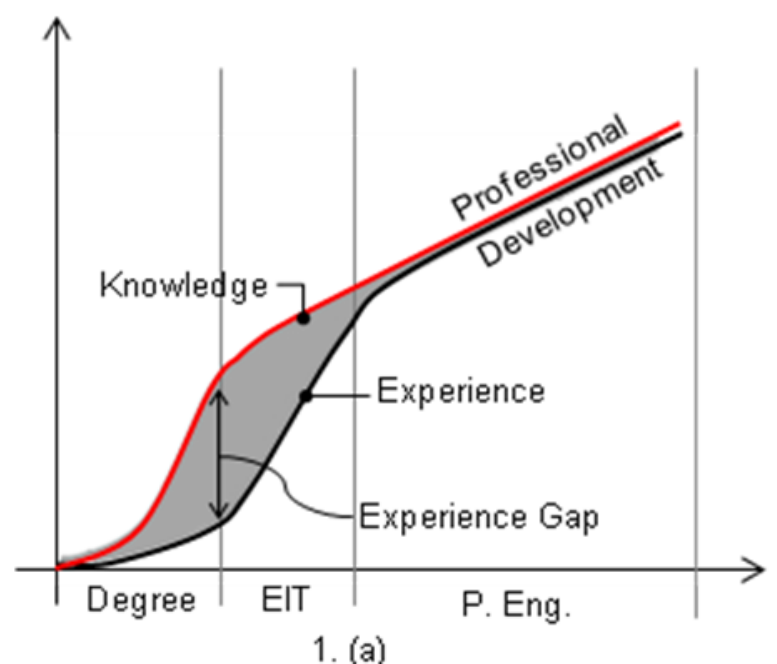

1. (a)

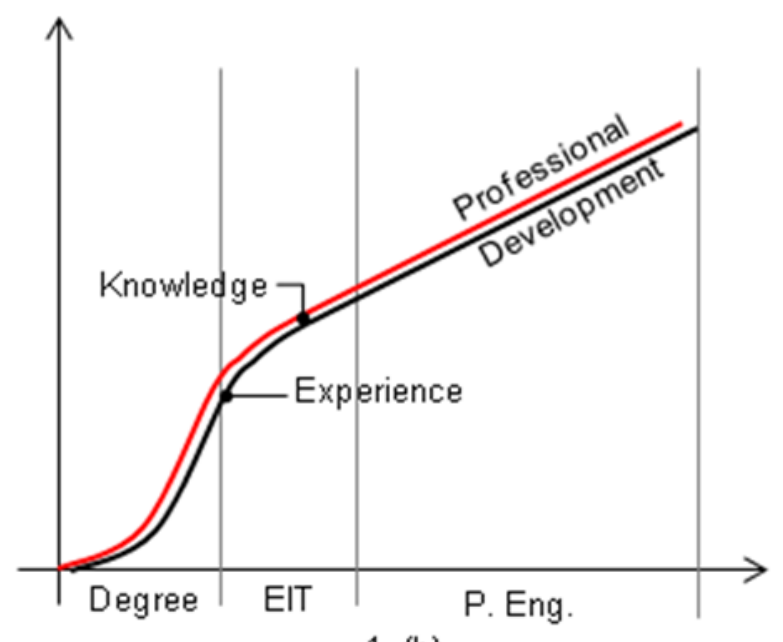

1. (b)

Figure 1: The acquisition of knowledge and experience in engineering education in (a) a more traditional model and (b) a more integrated model

More comprehensive than coop, a continuum of education which integrates knowledge and experience in a more cohesive way, as illustrated in Figure 1(b), can be achieved through the use of real-world design projects throughout the engineering curriculum (Chandrasekaran et al, 2012). In this way, knowledge and experience are interconnected at all stages of study which eliminates the "experience gap" typical of a more traditional engineering education model. This allows students to learn professional skills and to weigh complex environmental and ethical issues in an authentic professional practice context. Additionally, it challenges professors to connect all classroom content to real-world professional settings and encourages students to retain what they learn in class so that university is seen as professional training from the first day the students enter their studies. 


\section{INTEGRATION AT THE PROGRAM LEVEL}

\subsection{Sustainability within the Degree}

In this multidisciplinary degree, students graduate with the ability to design projects with consideration for sustainability at all steps in the design process. Rather than teaching sustainability with an 'end of pipe' mindset (Porter and Linde 1995), students are presented with different definitions of sustainability (WCED 1987, Engineers Canada 2006, Robert 1997, Hawken 1993). They utilize different models for considering sustainability, such as: life-cycle analysis (Young and Vanderburg 1994), clean technologies strategies (Beder 2000) the Natural Step (Robert 1997), and the Hanover principles (McDonough 1992), developing holistic solutions through the design projects.

Design textbooks for engineering students now highlight sustainability (Dym et al 2014) whereas before they commented primarily on the environment (Dym et al 2009). The textbooks purport that creative solutions will be discovered if students are open to working in multidisciplinary settings (Stephan 2015, Kibert 2012). This degree is tailored to allow students to self-discover multidisciplinary concepts to solve real problems.

\subsection{Professional Skill Development Coordinated Across the Program}

With a continuum of education mindset, students take a design course every semester during their degree, to put their increasing engineering knowledge to practice and learn professional skills. Rather than having an individual course on ethics, sustainability, social justice, or professional practice, modules are peppered throughout the design courses to regularly address this content. These modules, called professional skill developments (PSDs), are 1 hour long, rely primarily on active learning with a short 15minute lecture, and conclude with an assessment activity. PSDs utilize handouts and PowerPoint slides to reinforce points in lieu of textbooks, and are structured throughout the curriculum as shown in Figure 2, with additional detail for sustainability. Specific examples of Sustainability PSDs and their efficacy are discussed in section 4 .

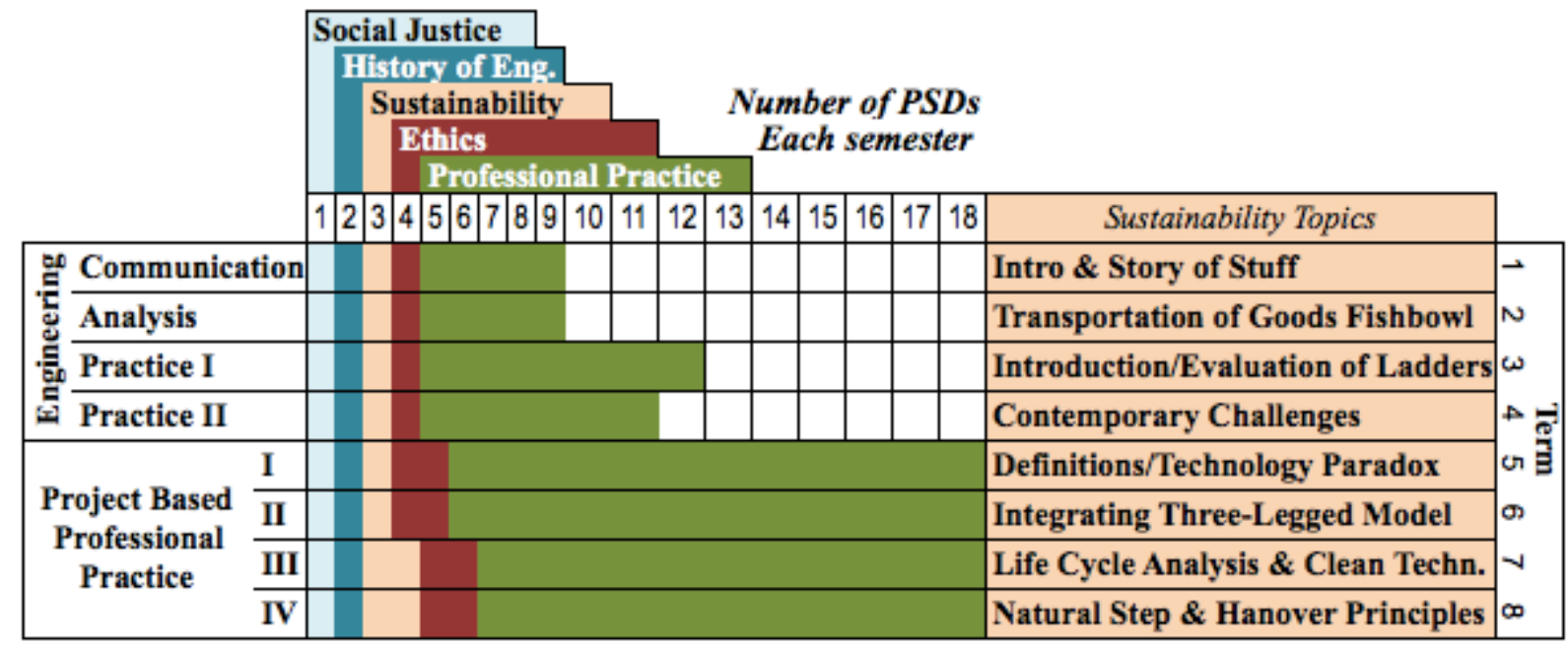

Figure 2: Professional skill development modules across the curriculum

The benefit of using PSDs as opposed to an entire course in that particular subject is that PSDs enforce the importance and connectedness of these often segregated concepts. In small doses, students are more receptive to accept the more abstract nature of these topics, as opposed to an entire course. Additionally, the repetition and review from previous sessions over time provides a better likelihood that students will retain the information and incorporate it in daily use. Additionally, these PSDs can be delivered regardless of the degree of sustainability of the particular project. 


\section{INJECTION WITHIN PROJECTS}

The most obvious injection of sustainability is within design projects, where problems can be selected that require sustainable solutions and the supporting documentation provides the flexibility to add sustainability sections and evaluations. However, regardless of the client or project, sustainability should be included as a constraint and an assessment to reinforce this as a regular part of an engineer's job. The amount of integration of sustainability within a project can be categorized into three levels:

- None, where sustainability is not mentioned or assessed

- Assignments, where project documentation includes sustainability in the evaluation of ideas, impact analyses, and recommendations

- Problem driven, where the client constrains the problem to focus on sustainability and thus it is addressed in all steps in the design process.

Figure 3 shows how sustainability is injected into the projects over the degree, specifying level of integration and duration of projects.

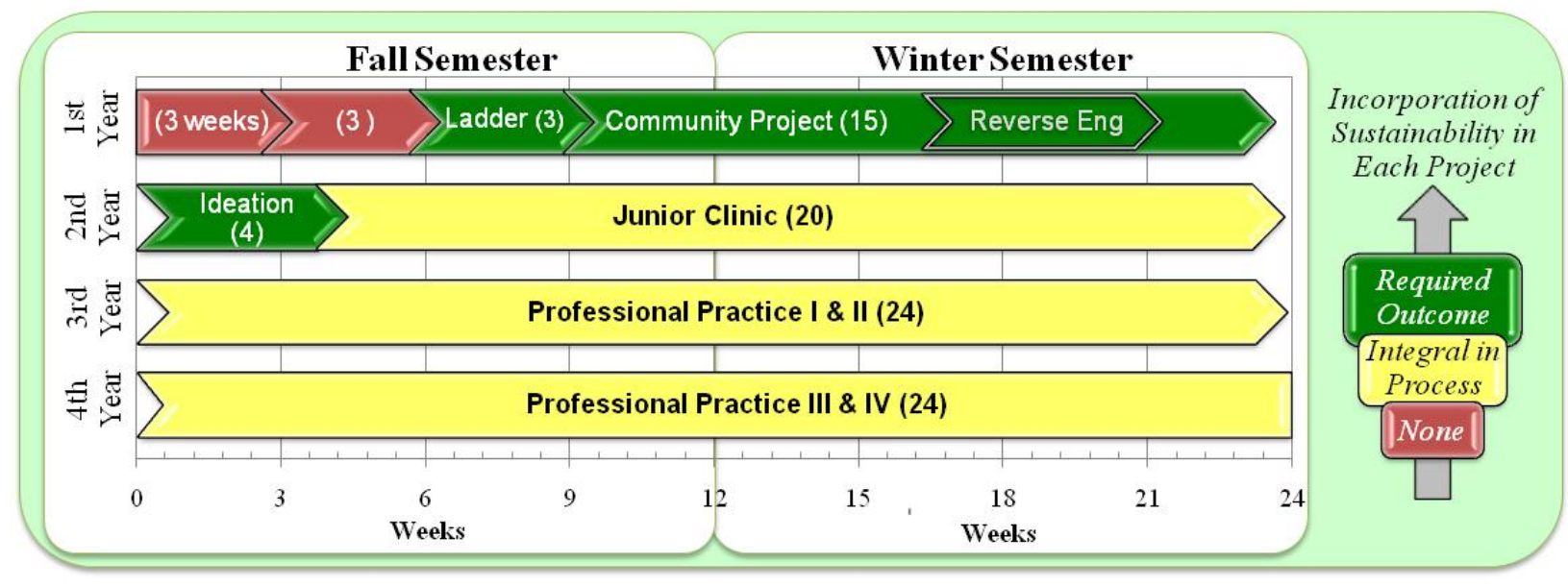

Figure 3: Project duration and how sustainability is incorporated in each project

The first two projects shown in Figure 3 do not incorporate sustainability. While these should be minimized, there is a necessity, especially in the first design course, to avoid overwhelming the student with too many objectives in the project. These two projects are focused on ideation and learning how to write technical reports, and do not proceed past the ideation/report phase. The third project introduces sustainability as a major focus, asking the students to redesign and build a ladder that is multipurpose and sustainable. This gives students the opportunity to explore the definition of sustainability and employ the minimization, reuse, and repurposing of materials. To reinforce the importance of reuse and repurposing, there is no budget provided. This very tight constraint forces the students to reimagine a ladder and explore the definition of sustainability. Either they plan to build only one, focusing on repurposed materials, or they find more organic materials in order for the design to be mass-produced. Students also produce requirements from the client's vague description of sustainability. This is an extremely enriching conversation as the students begin to see that they may not initially recognize what 'sustainability' implies. It also helps clarify the intent and specificity of requirements.

The final project of the fall semester continues through the entire winter semester and gives students their first interaction with an external client. For the community project, a client from a local or global organization proposes a general problem for all of the students to solve. For example, in 2013-2014, students worked with a new, large community garden organization to design irrigation, transportation, fertilization and cooking devices as well as educational demonstrations. The broad problem statement provides students an opportunity to identify specific problems, a step that is often performed by the professor due to time constraints. In this first step of problem identification and development, students 
can explore the sustainability of the current state of the problem using techniques learned in the ladder project to determine whether a change is even needed, before proceeding to research or ideation. Within this project, a 3-week reverse engineering exercise asks students to understand and evaluate an existing solution before finalizing one of their own. This allows the introduction of a number of sustainable concepts including life-cycle analysis and reliability. Students respond very well to this part of the community project, as many have never considered what fixtures are used on objects or what happens after an item is thrown out. The students eventually build, test, and present their devices at a public exposition.

The second year begins with a short duration project that requires a lot of creativity for a very focused problem. Past projects have included Rube Goldberg contraptions where students took 30 steps to water a plant, devices to walk on water, and gliders for a scaled-down Flugtag. The students are given a budget of $\$ 20$, which constrains material selection to favour repurposing. In this project, students perform a specific evaluation of the sustainability of their ideas from a life-cycle perspective and well as determine the energy requirements to produce the materials. Students eagerly show their creativity in ideation and often produce amusing, albeit sometimes far-fetched descriptions of the sustainability of their device. While the project requirements vary each year, the intent is for students to develop critical thinking skills, experience the design process, and practice project documentation. The documentation is assessed for completeness and professionalism. .

The junior clinic project pairs each group of four students with an individual client. Some of the clients demand highly sustainable solutions, but most projects are industry based where sustainability is not the focus. Over the two semesters, students methodically follow the design process to eventually build, test, and present their devices at the public exposition. The 'assignments' approach used here is the most comparable to industry, so it's especially important for students to learn how to incorporate sustainability into a design project. However, it is more effective to inject sustainability through frequent discussions at many points in the design process, questioning students' ideas and focusing questions on sustainability, rather than requiring specific assignments. Suggested discussion points are shown in Figure 4.

\begin{tabular}{|l|l|}
\hline Evaluation of current state of problem \\
\hline Research into sustainable alternatives \\
\hline Development of constraints or requirements \\
\hline Addition of evaluation criteria for durability, material selection \\
\hline $\begin{array}{l}\text { Assessment of environmental impact of chosen solution } \\
\text { for global projects }\end{array}$ \\
\hline Reduction of materials, by-products, and waste \\
\hline Reduction of manufacture process to reduce steps in production \\
\hline Plan for thorough testing to improve product efficiency and life \\
\hline Analysis of reliability of device \\
\hline Overall evaluation of sustainability of device \\
\hline Recommendation to client includes sustainability considerations. \\
\hline
\end{tabular}

Figure 4: Assignments to inject design into design projects 
Often through these discussions, students don't realize they are performing sustainability assessments, which can have a negative 'green' connotation for some students. The efficacy of this frequent questioning ingrains the necessity to constantly improve their ideas. Students vocalize that it is more difficult to produce sustainable designs rather than their constraint-free solution, however being forced to consider sustainability often produces a better product as students have put more thought into each step.

The professional practice projects in the third and fourth years, enable students to work more closely with industry, with the possibility of a two-year project. There are twice as many sustainable professional skill development modules in the final two years and the focus shifts from ideologies to analyses, as was shown in Figure 2. The same techniques are used from the junior clinic, with the addition of specific analyses for reliability, life-cycle, and material reduction.

A balanced plan at the program level is necessary to incorporate multiple levels of sustainability in the different projects, as students tire of too many 'green' projects and it's necessary for them to see how sustainability exists in industry. Additionally, there are some projects that do not include sustainability in any way, due to time constraints, knowledge level of students, and narrow objectives of the project.

\section{INSTRUCTION WITHIN COURSES}

The professional skill development (PSD) modules allow for short bursts of activity and instruction, keeping the topics engaging, for classes of 50 students. A cross-section of formats are selected to highlight the variability in learning and assessment techniques. As listed in Figure 2, the first introduction to sustainability is using the controversial Story of Stuff (2013) video. Students are asked to watch the video and a critique of the video. When the students come to class, they work first in small groups then as a class to discuss the content of the video and if there were any aspects of it that they found surprising. Next the counter argument is discussed. Students provide a summary and two points of critical thinking for assessment, as this course is focused on communication. This PSD is delivered during the ladder project, so the students have begun to think about sustainability topics, and the objective is to make them think critically about what they read and hear, not just blindly accept information as facts. Students enjoy the video and it helps solidify sustainability as a concrete contemporary topic for them to discuss, as opposed to the current project for one specific client.

In the winter semester, students engage in a fishbowl debate about the most sustainable form of transportation of goods. Initially small groups are formed to discuss the benefits and drawbacks of the three proposed ways to transport items: trains, planes, or trucks. Then students are randomly assigned to a larger group representing:

- $\quad$ Truck industry

- Airline industry

- Train industry

- Environmental activists

- Government agencies

- Consumers.

Each larger group formulates arguments supporting their position, against other groups' positions, and anticipates counter-points against their position. A fishbowl is then held where one person from each group sits in a circle and debates to determine which mode of transportation is the most sustainable for transporting goods. In a fishbowl, students can 'tap in' to replace the person who represents them so eventually many students become involved in the debate. This is a very interactive PSD that helps develop students' critical thinking, especially when anticipating counter-points. Students are assessed on a reflection submitted after class based on their understanding of the topic, arguments presented, and rebuttal of counter-points. The formats of the PSDs change each time, to avoid monotony. This particular format allows for many students to be involved and have a large class discussion (without a lecture), and integrates some of the quieter students in the small groups before the fishbowl begins. The resolution is always different, generally dependent on the persuasive ability of the representative, but the students 
leave having considered six different viewpoints and are now aware that goods do not appear on shelves without effort.

In the second year, the sustainability, social justice, and elevator pitch PSDs are combined into one module. The flexibility of the PSDs allows conceptual topics (sustainability or social justice) to be combined with skills (elevator pitch). The goals of this PSD are to:

- Learn an official definition for sustainability (WCED 1987)

- Learn an official definition for social justice

- Develop critical thinking skills by comparing the two concepts through small group discussion

- Evaluate the sustainability of the first year students' ladder projects

- Practice delivering elevator pitches representing one of the ladders.

There are many parts to this PSD, but each is short. Students first debate the difference between social justice and sustainability, both seen as globally important issues but two different concepts. Students then evaluate designs of other students, on a project that they completed the previous year, so there is familiarity and novelty. Finally, students have the opportunity to practice delivering elevator pitches (sixty second presentations of ideas) by persuading a partner that their newly adopted ladder is the most sustainable. This requires students to consider the sustainability, develop persuasive arguments, tailor the arguments to the most important, and practice speaking. Students are assessed on their engagement during the elevator pitches, as all of the students are actively involved and excited (in order to better persuade). There are no spectators though some students are more reserved in their delivery. It is a lot to fit into a short period, but compares two important topics and again changes the format of delivery.

As students mature in their abilities, the PSDs increase in complexity, from primarily focusing on critical thinking and awareness, to gaining knowledge, to using knowledge to perform analyses. Assessment techniques vary based on the PSD, from written reflections to oral reports, and measure only the skill for that PSD. While the previously stated advantages to the PSDs are numerous, there are two challenges that must be addressed:

1. A cross-curriculum platform is required to best deliver a comprehensive, modular selection of PSDs, though individual PSDs can be used in any course.

2. While students are assessed in each PSD, there is no exam for students to 'cram'. This active learning approach follows the continuum of education in which tests should not be required, but traditionalists are uncomfortable without a formal final assessment.

The first challenge is overcome by careful program-level planning, and the second challenge is outweighed by the benefit of regular acquisition of knowledge and immediate practice in design projects.

\section{CONCLUSION}

In place of a course in sustainability, a program, project, and course level integration has been successfully adopted to incorporate professional skills required of an engineer, such as ethics, professional practice, social justice, and sustainability. At the program level, students come into a professional environment in a continuum of education through multi-disciplinary design projects. Projects vary by duration and topic and have different clients based on the specific project objectives. At the project level, sustainability can be incorporated as defined in the problem or through assignments and regular discussion. At the course level, professional skill developments (PSDs) provide repetitive, gradual preparation for professional practice. Feedback from former students is positive, though gathered anecdotally. Students contend that the content from design courses and PSDs were immediately recognizable in industry, and they felt better prepared for their jobs. In order to produce the well-rounded engineers that industry demands, education methods must develop to meet the challenge. 


\section{References}

Accreditation Board for Engineering and Technology (ABET). 2015. "Criteria for Accrediting Engineering Programs." Retrieved January 24. http://www.abet.org/uploadedFiles/Accreditation/Accreditation_Step by_Step/Accreditation_Documents/Current/2015-2016/E001\%2015-16\%20EAC\%20Criteria\%2011-714.pdf.

Beder, S. 2000. "The Role of Technology in Sustainable Development." In Social, Ethical, and Policy Implications of Engineering, Selected Readings, edited by Herkert, JR, 230-5. IEEE.

Canadian Engineering Accreditation Board (CEAB). 2014. "Accreditation Criteria and Procedures". Retrieved January 24. http://www.engineerscanada.ca/sites/default/files/2014_accreditation_ criteria_and_procedures_v06.pdf.

Chandrasekaran, S., Stojcevski, A., Littlefair, G. and Joordens, M. 2012. "Learning through Projects in Engineering Education" 2012 SEFI European Society for Engineering Education Annual Conference, Thessaloniki, Greece, 2012.

Dym, C. L., Little, P. and Orwin, E. J. 2009. Engineering Design: A Project-Based Introduction. 3rd ed. John Wiley \& Sons, Hoboken, NJ, USA.

Dym, C. L., Little, P. and Orwin, E. J. 2014. Engineering Design: A Project-Based Introduction. 4th ed. John Wiley \& Sons, Hoboken, NJ, USA.

Engineers Canada. 2006. "National Guideline on Environment and Sustainability". Retrieved January 24. http://www.engineerscanada.ca/sites/default/files/guideline_enviro_with.pdf.

Engineers Canada. 2013. "National Guideline for Engineer In Training Program”. Retrieved February 1, 2015. http://www.engineerscanada.ca/sites/default/files/sites/default/files/guideline_eit.pdf.

Hawken, P. 1993. The Ecology of Commerce: a Declaration of Sustainability. Harper Business, New York, NY, USA.

Ingold, T.S. and Miller, K.S. 1983. Drained Axisymmetric Loading of Reinforced Clay. Journal of Geotechnical Engineering, ASCE, 109(2): 883-898.

Kibert, C. J. et al. 2012. Working Toward Sustainability: Ethical Decision Making in a Technological World. John Wiley \& Sons, Hoboken, NJ, USA.

McDonough, W. 1992. The Hannover Principles: Design for Sustainability. Germany: EXPO 2000 The World's Fair. http://www.mcdonough.com/principles.pdf

Noyes, C.R. and Gordon, J. 2011. "The Academic Effects of Cooperative Education Experiences: Does Co-op Make a Difference in Engineering Coursework?" 118th Annual Conference of the American Society for Engineering Education, Vancouver, Canada, 2011.

Porter, M. E. and Linde, C. 1995. "Green and Competitive: Breaking the Stalemate." Harvard Business Review. Accessed January 24. http://www.uvm.edu/ gflomenh/ENRG-POLPA395/readings/Porter_Linde.pdf

Robèrt, K. H. 1997. The Natural Step: a Framework for Achieving Sustainability in our Organizations. Pegasus Communications, Inc, Cambridge, MA, USA.

Stephan, E. A. et al. 2015. Thinking Like and Engineer: An Active Learning Approach. Pearson, Upper Saddle River, NJ, USA.

Story of Stuff Project. 2013. "Story of Stuff." Retrieved January 25. http://youtu.be/cpkRvc-sOKk.

World Commission on Environment and Development (WCED). 1987. Our Common Future. Oxford University Press, Oxford, UK.

Young, S. B. and Vanderburg, W. H. 1994. "Applying Environmental Life-Cycle Analysis to Materials." JOM, 46(4): 22-27. 